trations, for practical purposes, but the fact that Gerlach did not attempt-accuracy in the fourth decimal detracts from his work.

Gerlach's table for $20^{\circ} \mathrm{C}$. should be discarded entirely, but it is not likely that this temperature is used to any extent, the temperatures mostly in use being $15^{\circ} \mathrm{C}$., $15.5^{\circ} \mathrm{C} ., 25^{\circ} \mathrm{C}$., and $60^{\circ} \mathrm{F}$.
New tables should be prepared for these temperatures, but until this is done the following rule can be adopted with the assurance that one will not be very far from the truth:

For $15^{\circ} \mathrm{C}$. use Gerlach's table for that temperature; for $15.5^{\circ}$ and $60^{\circ} \mathrm{F}$. deduct 0.0002 from the specific gravity shown in Gerlach's table for $15^{\circ} \mathrm{C}$. (for the higher percentages); and for $25^{\circ} \mathrm{C}$. use Gerlach's table for $20^{\circ} \mathrm{C}$.

\title{
The Sewage Testing Station of the Illinois State Water Survey Division
}

\section{By Edward Bartow}

DepartMent OF Chemistry, State UNIVERSity OF IOWA, IOWA City, IOWA

The Illinois State Water Survey began the study of the activated sludge process of sewage treatment in November 1914, and had progressed by stages through bottle experiments, experiments in a box 9 in. square and $4 \mathrm{ft}$. deep, comparative experiments in four tanks $3 \mathrm{ft} .6 \mathrm{in}$. square and $10 \mathrm{ft}$. deep, all on the fill and draw system, to experiments in the original Champaign septic tank $18 \mathrm{ft}$. by $49 \mathrm{ft}$. and $9 \mathrm{ft}$. deep, working on the continuous flow system.

Combined with the study of the process were studies of the amount of oxygen in the influent and effluent air, the bacterial flora, and the fertilizer value of the sludge formed.

The results obtained were very good, and the continuance of the work was planned, when it became necessary to discontinue it almost completely because several of the staff were called upon to enter the Army. The same conditions existed almost everywhere, and little that was new had been learned about the process by the fall of 1919 , when members of the staff returned to the Division.

A small appropriation had been made for the biennium 1917-19, which was not used and had been reappropriated for the biennium 1919-21. With this as a nucleus the testing station is being revived. The Division funds have been supplemented by contributions or loans of instruments, apparatus, and machinery. The several Sanitary Districts in the State have promised their coöperation and support. Several manufacturing concerns have loaned apparatus for the work. Tanks, machinery, a blower, a filter press, a continuous filter, and a dryer have been obtained in this way.

It is not proposed to confine the experimental work to the activated sludge process, but to try other methods of sewage treatment as time and funds permit. Many cities in Illinois are located on large streams into which a partly purified sewage can be emptied. It is therefore proposed to construct and test the efficiency of methods of primary treatment, such as the Doten tanks used in the Army, the separate digestion tanks used by the Housing Corporation, and other similar schemes that may be developed.

Owing to the limited amount of funds, all of the schemes cannot be tried at once, and it has been decided to make a study first of the Dorr-Peck modification of the activated sludge process, with additions so that the process will be complete from the raw sewage to the clarified and purified effluent, and the dried sludge ready to be used as a fertilizer.

The plant is located on land belonging to the city of Champaign, near the outfall of the Champaign sewer. The site is well adapted to the purpose. Before entering the distributing chamber, formerly used in connection with the Champaign septic tank, the sewage is about on a level with the ground, and after passing the manhole the by-pass is enough lower to allow the sewage drawn from the upper level to flow by gravity through a small grit chamber, and

1 Presented before the Division of Water, Sewage, and Sanitation at the 60th Meeting of the American Chemical Society, Chicago, Ill., September 7 to 10,1920 . through any screening devices that are to be tested, and then to return to the sewer.

\section{SCREENING}

Only one screen has been installed, used by the designers for screening tannery wastes. The water passes from the outside to the center of a revolving drum. The drum is rotated at such a rate that some of the screened liquid is carried up the inside of the drum, and flows out through the holes in the screen, thus automatically cleaning the outside surface of the screen. While it is planned to have each part of the plant large enough to treat 100,000 gallons of sewage daily, the screen will be large enough to handle 200,000 gallons, and it will be possible to test its capacity, as the branch tapped into the main sewer will carry 400,000 gallons. There are two notable advantages in the arrangement of the system:

1-The amount of sewage that can be screened is not limited by the capacity of pumps.

2-The pumps will deliver screened sewage and there will be no danger of clogging the suction pipe.

An extra drum will be provided so that, with practically no loss of time, the drums can be changed and different sizes and different arrangements of holes can be tried.

\section{Pumping}

The screened sewage passes from the interior of the drum through an opening in one end to the pump pit, from which it is delivered to the aeration compartment of the tanks by two centrifugal pumps having a combined capacity of 200,000 gallons. It is proposed to limit the flow, at least at first, to 100,000 gallons daily.

\section{AERATION}

The sewage enters the lower part of a cylindrical tank $17 \mathrm{ft}$. in diameter and $13 \mathrm{ft}$. deep. The tank is divided horizontally into two nearly equal parts by a tray, which is slightly higher in the middle than at the edges. The air is forced into the aeration chamber through filtros plates arranged in an inscribed square. Any sludge that may settle to the bottom is carried by scrapers toward the circumference. The air carries the sludge and sewage to the under side of the tray, which holds the air in suspension, as it travels toward the center to a level above that of the liquid in the tank. As the air escapes part of the liquid passes down a central downcast well into the lower compartment to be mixed again with the incoming sewage, and part passes into the upper compartment that serves as a settling chamber. Holding the air in the lower compartment below the tray has resulted in a great reduction of the amount of air required. According to tests made at Mt. Vernon, N. Y., the process will operate with one-third of the air required when it is allowed to rise directly to the surface and escape.

\section{Sludge Separation}

Part of the liquid from the upcast well pisses over the outer rim, which can be raised and lowered to goit the proportion desired in the settling chamber. In the settling cham- 
ber the flow of the clear liquid is toward the outer rim of the tank, where it flows into a trough or launder and runs away. The sludge is carried by revolving plows to the outside of the chamber where it drops down sludge wells to the aeration chamber to be mixed again with the sewage and air. The greater part of the purification is found to take place in the earlier stages of the aeration, so that it is proposed to run two tanks in series, using more air in the first tank, and allowing the sludge to collect in the settling tank till it flows over the rim into the trough, and then to the second tank where it receives a second treatment with a smaller amount of air. Sludge in excess is removed from the sludge wells in the second tank.

\section{Disposal of EFFLUtent}

The effluent from a properly operated activated sludge plant is so stable that it can be allowed to flow into the dry bed of a stream, or into a pond. It is proposed to allow the effluent from the tanks to flow into a pond formed from a former creek bed when the course of the stream was changed by the dredging of a drainage ditch. The pond will be about $30 \mathrm{ft}$. wide and $400 \mathrm{ft}$. long. During the summer an attempt will be made to grow fish in the pond. Fish have been successfully grown in sewage diluted 1:3 at Strasburg by Hofer, and at Bergedorf, near Hamburg, in the effluent from Imhoff tanks and sprinkling filters. If the experiment is successful, it will show the possibilities of improving the condition of many streams in the state, in which fish no longer exist.

\section{Sludge Dewatering}

Experiments with a small plate press and with a 12-in. centrifugal machine have already been tried. Enough has been learned to lead to the conclusion that the sludge must not be at all stale. If the dissolved oxygen disappears, the sludge gets into a condition that prevents filtration. Plans are in view to re-aerate the sludge after it is removed from the tank and thus prevent the development of anaerobic bacteria, which may be directly or indirectly the cause of filtration difficulties.

The success of the activated sludge process depends on the reduction of the cost of the air, and on the successful dewatering and drying of the sludge. Many attempts have been made, but we are not sure that any have been entirely successful. We may be repeating the work of others, but we believe with some modifications.

The centrifuge will be tried further. Most of our tests have given sludge with about 90 per cent of moisture. We hope to reduce this. A 15-plate leaf press with plates 28 in. in diameter has been ordered, and a continuous filter is already at the plant. The dewatering is only preliminary to the drying, which will be a new system.

\section{Sludge Drying}

So far as we know attempts to dry sludge have been made with the direct heat dryers. With these it is necessary to construct a large dust chamber, and a fume chamber in which the escaping gases can be washed, before they are allowed to escape from a high chimney. We are proposing to use an indirect heat dryer. The temperature at no point in the dryer rises above $205^{\circ} \mathrm{F}$., and the moisture content of the sludge in several test runs has been reduced from 80 to 84 to 3 to 10 per cent without dust or unpleasant odors.

The members of the Division staff have taken a great deal of interest in the plans for the Station, and any success obtained will be due to their efforts and to the support given by the manufacturers and Sanitary Districts that are assisting in the work.

\title{
ADDRESSES AND CONTRIBUTED ARTICLES
}

\section{Dyes Derived from Beta-Oxynaphthoic Acid and from $\mathbf{J}$-Acid, with Reference to the Chemical Foundation Patents ${ }^{1}$}

\author{
By A. Willard Joyce \\ Chemical Foundation, Inc., 81 Fulton St., NEW York, N. Y.
}

The dyes derived from $\beta$-oxynaphthoic acid and the arylamides of $\beta$-oxynaphthoic acid, chiefly the anilide known as Naphthol AS, form a very valuable class, which has received little or no attention from manufacturers of dyes in this country. The Chemical Foundation owns a number of patents which cover the processes for making some of these dyes, as well as the dyes themselves, and in some cases processes for applying the dye or its intermediates. It is the purpose of this paper to bring to your attention these patents which bear upon this particular group of colors.

The dyes derived from 2,5,7-aminonaphthol sulfonic acid, or $\mathrm{J}$-acid, and $\mathrm{J}$-acid derivatives will be discussed in a similar way.

\section{DYES DERIVED FROM $\beta$-OXYNAPHTHOIC ACID AND ITS} ANILIDES

In a recent paper by E. R. Brunskill ${ }^{2}$ the advantages of the colors made by substituting the $\beta$-oxynaphthoic anilides for $\beta$-naphthol in the ice process were discussed.

It is well known that the colors made from the free $\beta$-oxynaphthoic acid with amines or sulfonated amines have the serious fault of washing out easily, and are not fast to rubbing. The anilides of this acid give colors which are much faster, so that the greatest development of these colors for dyeing by the ice

1 Presented before the Division of Dye Chemistry at the 61st Meeting of the American Chemical Society, Rochester, N. Y., April 26 to 29, 1921.

2 This Journal, 13 (1921), 309. process has been by using combinations with the anilides of $\beta$ oxynaphthoic acid, chiefly Naphthol AS or $\beta$-oxynaphthoic acid anilide.

The colors made from the free $\beta$-oxynaphthoic acid have found their greatest use as lake pigment colors. These are usually made in the form of their barium, calcium, and lead salts, which are noted for their insolubility in water and oil and for their brilliancy of shade.

The development of colors for use as lakes from $\beta$-oxynaphthoic acid or Naphthol D has been made by several of the large German dye companies, chiefly the firm of Meister, Lucius \& Bruning. The first pigment color of this class which they patented was Lake Bordeaux B, Schultz Number 179. This dye is made by combining diazotized 2-naphthylamine-1-sulfonic acid (Tobias' acid), with Naphthol D.1 As a color lake, this dye has no demand, and is not considered valuable commercially.

Another pigment belonging to this class developed by Meister, Lucius \& Bruning, is Hansa Rubine, which is distinguished by its clear bluish red tint, insolubility in oil, and fastness to light. The dye used in making this pigment is made from 2,4dinitroaniline-6-sulfonic acid and Naphthol D.2

The lake pigment known as Red for Lake $C$ is made from the dye produced by combining 2-chloro-5-toluidine-4-sulfonic

\footnotetext{
1 U. S. Patent 858,065.
}

U. S. Patent 978,865 . 